Endocrinol. Japon. 1990, 37 (4) 571-576

\title{
Tuberculous Thyroiditis and Miliary Tuberculosis Manifested Postpartum in a Patient with Thyroid Carcinoma
}

\author{
KAZUOKI HIZAWA, Ken OKAMURA, KaORI SATO \\ TAKEO KURODA, MOTOTAKA YOSHINARI \\ Hiroshi IKENOUE, and Masatoshi FUJISHIMA
}

Second Department of Internal Medicine, Faculty of Medicine, Kyushu University, Maidashi, Higashi-ku, Fukuoka 812 Japan

\begin{abstract}
Right nodular goiter with diffuse miliary shadow on chest roentgenogram was found in a postpartum febrile woman. Transbronchial lung biopsy revealed tuberculous granuloma and acid-fast bacilli were found by aspiration cytology of the thyroid. Although chemotherapy was effective, the thyroid nodule remained palpable and the serum thyroglobulin level remained high. Subtotal thyroidectomy revealed papillary carcinoma associated with tuberculosis and lymph nodes metastasis. This seems to be the first case report of a patient with tuberculous thyroiditis, coexisting with thyroid carcinoma, diagnosed by aspiration cytology and treated prior to surgery.
\end{abstract}

In the 19th century, microscopic involvement of the thyroid gland was found in $7 \%$ of the patients with disseminated tuberculosis (Barnes and Weatherstone, 1979). Tuberculosis of the thyroid gland was found in about $0.1 \%$ of the partial thyroidectomy specimens examined at the Mayo clinic between 1920 and 1931 (Rankin and Graham, 1932). Since the introduction of chemotherapy, however, tuberculous thyroiditis has been thought to be extremely rare, although it can be potentially lifethreatening without adequate therapy (Barnes and Weatherstone, 1979). The

Received June 19, 1990

Correspondence to: Ken Okamura, M. D. Second Department of Internal Medicine, Faculty of Medicine, Kyushu University, 3-1-1, Maidashi, Higashi-ku, Fukuoka 812 Japan thyroid gland itself is resistant to infection because of anatomical features including its rich system of arterial supply and venous or lymphatic drainage with a thick fibrous capsule. The high concentration of iodinecontaining chemicals in the gland may also have an anti-microbiotic effect (Burhans, 1928). Infectious thyroiditis may occur when these anatomical barriers are destroyed by a pre-existing thyroid disorder, such as thyroglossal duct fistula, adenoma or adenomatous goiter (Berger et al., 1983).

We describe a rare case of tuberculous thyroiditis which occurred after a pregnancy and was diagnosed by aspiration cytology of the thyroid. The serum thyroglobulin level remained high even after the improvement following chemotherapy, suggesting the presence of a co-existing thyroid tumor. 


\section{Cses Report}

A 33-year-old Japanese woman (No. 8570) was admitted to the Second Department of Internal Medicine, Kyushu University, on August 20, 1986. She had had slight fever and a productive cough for six months. The symptoms were exacerbated after she delivered her second child 2 months before admission. There was no previous or family history of tuberculosis or thyroid disease. She was a well-nourished woman with normal blood pressure and pulse rate. Her body temperature was $37.6^{\circ} \mathrm{C}$. Physical examination revealed a hen-egg sized hard nodule in the right lobe of the thyroid and a few bean sized hard lymph nodes in the right cervical region. The overlying skin was normal. Crepitant rales were audible in the chest. Ophthalmoscopic examination revealed a yellowish round nodule in the left retina. Laboratory findings were as follows : hemoglobin $118 \mathrm{~g} / \mathrm{L}$, leukocyte count $8200 / \mathrm{mm}^{3}$ with $74 \%$ neutrophils, $17 \%$ lymphocytes and 3\% eosinophils and an erythrocyte sedimentation rate of $97 \mathrm{~mm}$ /hour. Tuberculin skin test with purified protein derivative (PPD) showed $1.8 \times 1.3 \mathrm{~cm}$ of erythema. Serum $\mathrm{T}_{3}$ was $1.7 \mathrm{nmol} / \mathrm{L}$ (normal 1.4-3.2 nmol/L), $\mathrm{T}_{4} 127$ $\mathrm{nmol} / \mathrm{L} \quad(58-161 \mathrm{nmol} / \mathrm{L}), \quad$ TSH $2.0 \mathrm{mU} / \mathrm{L}$ $(0.8-4.2 \mathrm{mU} / \mathrm{L})$ free $\mathrm{T}_{4} 17 \mathrm{pmol} / \mathrm{L}$ (10-27 $\mathrm{pmol} / \mathrm{L})$ and thyroxine binding globulin $27.7 \mu \mathrm{g} / \mathrm{ml}(12-30 \mu \mathrm{g} / \mathrm{ml})$. They were all within normal limits. Serum thyroglobulin, however, was increased to $295 \mathrm{ng} / \mathrm{ml}$ (normal less than $30 \mathrm{ng} / \mathrm{ml}$ ). Anti-thyroid autoantibodies to thyroglobulin and thyroid microsomal antigen were both negative. The chest X-ray film showed a diffuse miliary shadow of the lung with deviation of the trachea to the left (Fig. 1) and the neck radiograph showed minute calcification around the thyroid cartilage. Echographic examination of the thyroid revealed a mosaic-like structure with scattered calcification in the right lobe. A thyroid scan showed a cold nodule in the right lobe with a reduced uptake of ${ }^{123} \mathrm{I}$ and an enhanced uptake of ${ }^{201} \mathrm{~T} 1$ and ${ }^{67} \mathrm{Ga}$. ${ }^{67} \mathrm{Ga}$ was also taken up diffusely by the lung. Thyroidal radioactive iodine uptake at 24 hours was $16.9 \%$ (normal value $15.8 \pm 7.5 \%$, mean $\pm S D$ ).

Thyroid cancer with lung metastasis was first considered but was ruled out for the following reasons. The main distribution of the miliary shadows was limited to the upper lung field, and the transbronchial lung biopsy revealed a caseating tuberculous granuloma. A whitish necrotic fluid was obtained by aspiration cytology of the thyroid nodule in which acid-fast bacilli were present. Culture of the sputum revealed mycobacterium tuberculosis, confirming the diagnosis of pulmonary miliary tuberculosis with dissemination to the right thyroid gland. A yellowish round lesion in the left retina was also considered to be tuberculous damage. Antituberculous treatment with streptomycin, isoniazid and rifampin was begun. She became well with remarkable improvement in the signs of inflammation after 4 months treatment, and miliary shadows on the chest roentgenogram disappeared. However, the serum thyroglobulin level remained high $(117 \mathrm{ng} / \mathrm{ml})$ and the thyroid nodule remained palpable. A preexisting thyroid disorder was suggested and subtotal thyroidectomy with radical lymph nodes resection was performed on January 21, 1987, at the 1st Department of Surgery, Kyushu University. A well circumscribed yellow-red tumor was present in the right lower lobe and adhered to the sternothyroid muscle. It consisted of papillary carcinoma with calcification and tuberculous granuloma (Fig. 2). Metastasis to the cervical lymph nodes was also found.

The post-operative course was uneventful and serum thyroglobulin was no longer detectable after she was put on 1-thyroxine. 


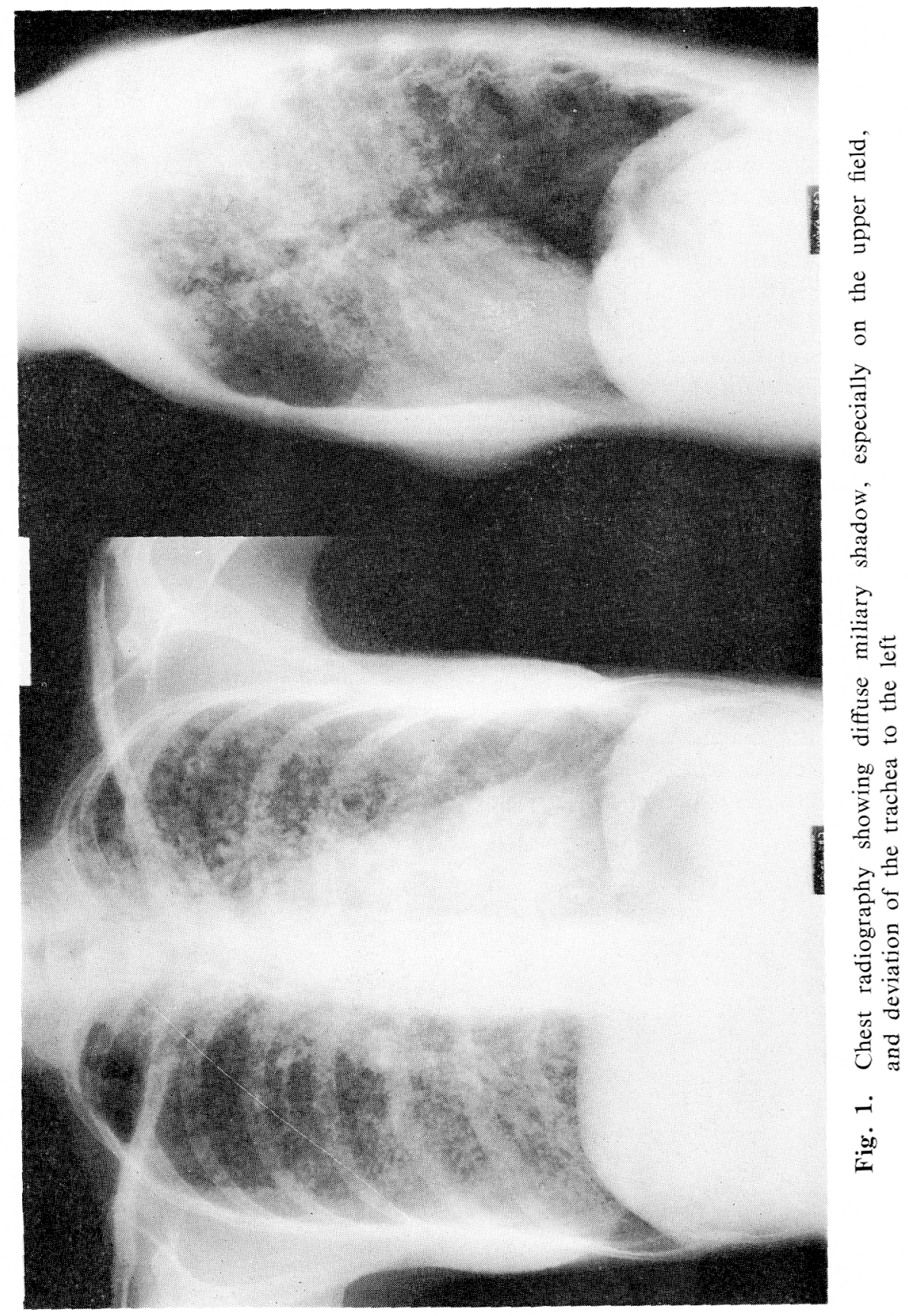




\section{Discussion}

The diagnosis of tuberculous thyroiditis might have been confused with that of subacute thyroiditis before the concept of subacute thyroiditis was established (Greene, 1971). Therefore, bacteriological confirmation with acid-fast bacilli within necrotic or abscessed thyroid gland should be made before the diagnosis of tuberculous thyroiditis is given (Barnes and Weatherstone, 1979). Berger et al. (1983) identified 21 patients with mycobacterial thyroiditis in the English literature between 1900 and 1980. Two additional cases in Thailand were reported in 1981 (Laohapand et al., 1981 ; Chandrcharoensin and Viranuvatti, 1981). In Japan, 7 cases, 2 men and 5 women aged 19 to 76 , had been reported and were reviewed by Kajiyama et al. (1988). The diagnosis of tuberculous thyroiditis was made from the histological findings only after surgery.

The most outstanding finding in our case was that the diagnosis of tuberculous thyroiditis was confirmed by aspiration cytology of the thyroid before surgery and chemotherapy was immediately initiated. Very recently, Sachs et al. (1988) reported an unusual case of tuberculous adenitis of the thyroid mimicking subacute thyroiditis. Although a fine needle biopsy was performed, the diagnosis was not confirmed before or at surgery because no stain or culture for mycobacteria was performed. When a necrotic mass or pus is obtained by aspiration cytology, bacteriological examination should be performed not only with Gram's stain but also with acid-fast stains.

The common type of involvement of the thyroid gland in tuberculosis used to be miliary spread to the thyroid, as part of the generalized dissemination and without clinical symptoms of thyroid disease (Barnes and Weatherstone, 1979; Rankin and Graham, 1932). The less common type is focal or caseous tuberculosis of the thyroid, presenting as a thyroid nodule (Laohapand et al., 1981; Kajiyama et al., 1988), as a thyroid abscess (Goldfarb et al., 1965; Johnson et al., 1973) or as diffuse thyroid enlargement (Barnes and Weatherstone, 1979). The patients are usually euthyroid, although Barnes and Weather-

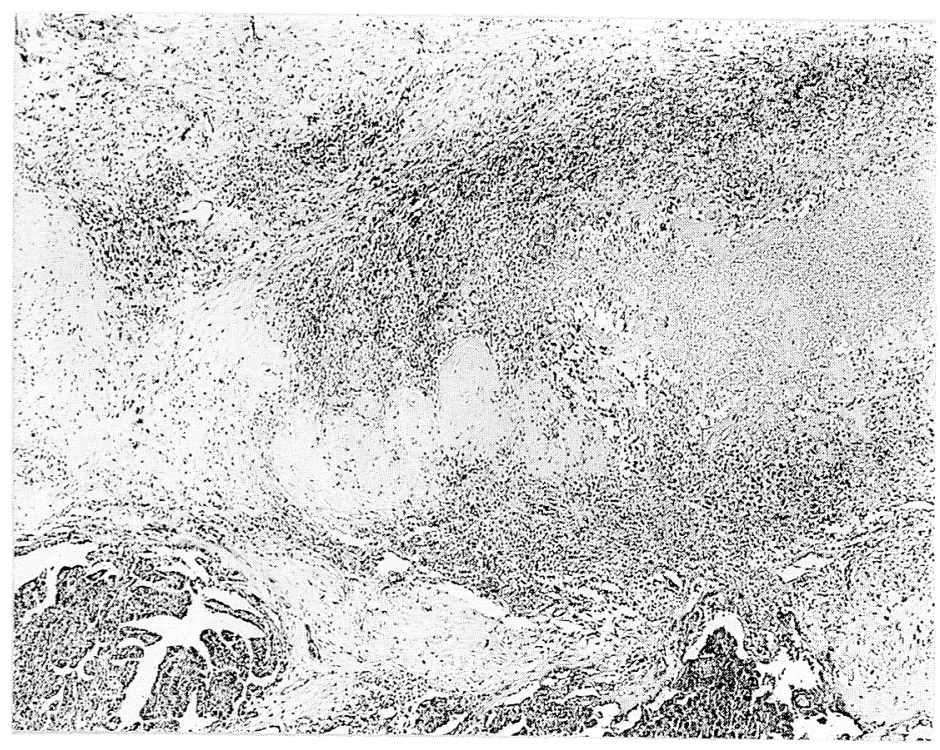

Fig. 2. Histology of the right thyroid nodule showing tuberculous caseating granuloma, coexisting with papillary carcinoma (hematoxylin and eosin stain $\times 40$ ) 
stone (1979) reported an unusual case with myxedema in which the thyroid gland was completely replaced by caseating granuloma and Kapoor et al. (1985) reported a tuberculosis of the thyroid gland associated with thyrotoxicosis.

In our patient, the thyroid function was normal. However, the serum level of thyroglobulin remained high even after she became well with chemotherapy. Although the measurement of serum thyroglobulin is of limited value in the differential diagnosis of nodular thyroid disease, it is useful for follow-up study of patients with thyroid disorders (Shlossberg et al., 1979). A pre-existing thyroid disease, such as thyroid carcinoma in our case, should be considered in patients with persistently increased serum thyroglobulin and palpable thyroid nodule.

In the review of infectious diseases of the thyroid gland, Berger et al. (1983) stressed that the most common determinant of thyroid infection appears to be preexisting thyroid disease. Burhans (1928) reported that 32 of 67 cases of thyroiditis followed chronic goiters and that infection generally involved only the previously diseased area of the thyroid. It is true that pre-existing thyroid disease is not the sole determinant of infectious diseases of the thyroid gland. Thyroid tuberculosis was described in only 21 or $0.1 \%$ of 20,758 tissue specimens examined at the Mayo Clinic (Rankin and Graham, 1932) and in only two of 74,393 consecutive thyroid biopsy specimens at an Italian center (Barnes and Weatherstone, 1979). After exposure to bacterial infection, additionol factors such as pregnancy or malnutrition may also be responsible for the precipitation of thyroid infection.

Pregnancy itself has little effect on the natural history of tuberculous infection and there is no risk of reactivation of pulmonary tuberculosis if there is adequate treatment (De March, 1975; Weinberger and Weiss,
1982). Several studies prior to modern chemotherapy, however, suggested an increased rate of aggravation of pulmonary tuberculosis during the first postpartum year, probably due to rapid hormonal changes, the nutritional strain, and insufficient sleep. The development of chemotherapy has not entirely eradicated the complicated management problems that can occur in pregnancy and there are reports of meningeal, miliary, and peritoneal involvement with tuberculosis during pregnancy, even in recent literature (Weinberger and Weiss, 1982).

We conclude that aspiration of the thyroid gland is useful for immediate diagnosis of tuberculous thyroiditis, and that the presence of a pre-existing thyroid disease should be considered in patients with infectious thyroiditis.

\section{Acknowledgments}

We thank Drs. K. Matsuo and M. Torisu of the First Department of Surgery, Kyushu University, for collaboration, and M. Ohara for comments.

\section{References}

Barnes, P. and R. Weatherstone (1979). Tuberculosis of the thyroid: two case reports. $B r$. J. Dis. Chest. 73, 187-191.

Berger, S. A., J. Zonszein, P. Villamena and N. Mittman (1983). Infectious disease of the thyroid gland. Rev. Infect. Dis. 5, 108-122.

Burhans, E. C. (1928). Acute thyroiditis : a study of sixty-seven cases. Surg. Gynecol. Obstet. 47, 478-488.

Chandrcharoensin, C. and V. Viranuvatti (1981). Tuberculous abscess of the retrosternal thyroid gland displacing the oesophagus. Diagn. Imaging 50, 29-31.

De March, A. P. (1975). Tuberculosis and pregnancy. Five- to ten-year review of 215 patients in their fertile age. Chest 68, 800804.

Goldfarb, H. D., Schifrin and F. A. Graig 
(1965). Thyroiditis caused by tuberculous abscess of the thyroid gland. Case report and review of the literature. Am. J. Med. $38,825-828$.

Greene, J. N. (1971). Subacute thyroiditis. Am. J. Med. 51, 97-108.

Johnson, A. G., M. E. Phillips and J. S. Thomas (1973). Acute tuberculous abscess of the thyroid gland. Br J. Surg. 60, 668-669.

Kajiyama, Y., M. Nobori, S. Saiki, et al. (1988). Tuberculous thyroiditis: report of a case with a review of the literature. Endocrine. Surg. 5, 113-118.

Kapoor, V. K., K. Subramani, S. K. Das, A. K. Mukhopadhyay and T. K. Chattopadhyay (1985). Tuberculosis of the thyroid gland associated with thyrotoxicosis. Postgrad. Med. J. 61, 339-340.

Laohapand, T., S. Ratanarapee, N. Chantarakul and A. Vitavasiri (1981). Tuberculous thyroiditis, a case report. J. Med. Assoc. Thai. 64, 256-260.

Rankin, F. W. and A. S. Graham (1932). Tuberculosis of the thyroid gland. Ann. Surg. 96, 625-648.

Sachs, M. K., G. Dickinson and K. Amazon (1988). Tuberculous adenitis of the thyroid mimicking subacute thyroiditis. Am. J. Med. 85, 573-575.

Shlossberg, A. H., J. C. Jacobson and H. K. Ibbertson (1979). Serum thyroglobulin in the diagnosis and management of thyroid carcinoma. Clin. Endocrinol. (Oxf.) 10, 17-27. Weinberger, S. E. and S. T. Weiss (1982). Pulmonary diseases. In: Burrow, G. N., Ferris, T.F. (ed). Medical complications during pregnancy. 2nd edition. W. B. Saunders, Philadelphia, pp. 405-434. 